\title{
Selective Thallium (I) Ion Sensor Based on Functionalised ZnO Nanorods
}

\author{
Z. H. Ibupoto, Syed M. Usman Ali, K. Khun, and Magnus Willander \\ Department of Science and Technology, Linköping University, Campus Norrköping, 60174 Norrköping, Sweden \\ Correspondence should be addressed to Z. H. Ibupoto, zafar.hussain.ibupoto@liu.se
}

Received 14 February 2012; Accepted 5 August 2012

Academic Editor: Jinhui Song

Copyright () 2012 Z. H. Ibupoto et al. This is an open access article distributed under the Creative Commons Attribution License, which permits unrestricted use, distribution, and reproduction in any medium, provided the original work is properly cited.

Well controlled in length and highly aligned $\mathrm{ZnO}$ nanorods were grown on the gold-coated glass substrate by hydrothermal growth method. ZnO nanorods were functionalised with selective thallium (I) ion ionophore dibenzyldiaza-18-crown-6 (DBzDA18C6). The thallium ion sensor showed wide linear potentiometric response to thallium (I) ion concentrations $\left(1 \times 10^{-7} \mathrm{M}\right.$ to $\left.5 \times 10^{-2} \mathrm{M}\right)$ with high sensitivity of $36.87 \pm 1.49 \mathrm{mV} /$ decade. Moreover, thallium (I) ion demonstrated fast response time of less than $5 \mathrm{~s}$, high selectivity, reproducibility, storage stability, and negligible response to common interferents. The proposed thallium (I) ion-sensor electrode was also used as an indicator electrode in the potentiometric titration, and it has shown good stoichiometric response for the determination of thallium (I) ion.

\section{Introduction}

When zinc, cadmium, and lead metals are produced by the burning of coal, during this thallium $\left(\mathrm{Tl}^{+1}\right)$ a poisonous metal ion penetrates into the atmosphere as a major waste product [1]. Thallium are dangerous to all people when they come in contact for very short time with the environment where amount of thallium ions is too much, and due to this they can suffer from the gastrointestinal aggravation as well as nerve problems [2]. The compounds of thallium in which two atoms of thallium (I) are present are very toxic such as thallium sulphate $\left(\mathrm{Tl}_{2} \mathrm{SO}_{4}\right)$, even the compounds containing single atom of thallium as thallium acetate $\left(\mathrm{CH}_{3} \mathrm{COOTl}\right)$ and thallium carbonate $\left(\mathrm{Tl}_{2} \mathrm{CO}_{3}\right)$. Furthermore, thallium (I) ion has the ability to replace $\mathrm{K}^{+1}$ in energizing the few vital enzymes such as ATPase and pyruvate kinase [3]. Thallium (I) is atoxic, when its concentration is very low as about $0.5 \mathrm{mg} / 100 \mathrm{~g}$ of tissue [4]. If thallium (I) ion concentration in the human body is present in excess for long time, this in result brings a change in the blood composition, harms liver, kidney, intestinal, testicular tissue, and causes hair loss [5]. Because of the poisonous effects of thallium (I) ion and its different chemical compounds, it is highly needed to measure the concentration of thallium (I) ion in real biological and environmental samples. There are many methods which have been used for the determination of thallium (I) ion such as spectrophotometric measurement, graphite-furnace atomic absorption spectrometric, flame atomic absorption spectrometric (FAAS) afterwards the extraction $[6,7]$, respectively, inductive-coupled plasma mass spectrometric (ICP-MS), voltammetry, and potentiometric methods. There are many advantageous of potentiometric technique such as cheap, simple, accurate, and easy to handle with the biological samples. The highness of this technique is lying on the fact that it uses the ion-selective electrodes, which are largely used for the determination of metal cations [8]. There is not so much work reported in the literature for the determination of thallium (I) ion, with the membrane electrodes due to lack in the selectivity in the presence of $1 \mathrm{~A}$ group metal cations, linearity, and resistance to the change in the $\mathrm{pH}$ of testing solution. However, different crown ethers were used as selective thallium (I) ionophore in the development of ion-selective electrodes, but many of them had low range of detection of thallium ion concentrations $\left(1 \times 10^{-5}-1 \times 10^{-1} \mathrm{M}\right)$. These ion-selective electrodes based on these crown ethers had also faced big problems during the construction and rarely detected the trace quantity of thallium (I) ions [9]. 
Today, the researchers are paying more attention to the nanomaterial-/nanostructure-based electrochemical sensors. Zinc oxide $(\mathrm{ZnO})$ nanomaterial is well known among other nanomaterials for its valuable applications in the field of biosensors and chemical sensors due to their high surface area to volume ratio.

Moreover, $\mathrm{ZnO}$ has strong ionic bonding characteristics about (60\%) and offered more resistance to dissolve at biological $\mathrm{pH}$ value. There are many ways to utilize the $\mathrm{ZnO}$ nanostructures in the field of electrochemical biosensing processes because of its ease in functionalization with selective membranes/enzymes. ZnO-nanostructurebased nanosensors have many unique properties, these nanosensors possess a small size and high surface area to volume ratios which results in strong signals, and higher catalytic property and allows the fast flow of to be tested electrolytically via sensor and thus show good sensitivity and a lower limit of detection (LOD) as compared to the sensors based on the bulk $\mathrm{ZnO}$.

Due to the high surface area to volume ratio of $\mathrm{ZnO}$ nanorods, these are the potential candidates for more sensitive nanochemical sensors $[10,11]$. $\mathrm{ZnO}$ nanorods are $\mathrm{n}$ type semiconductors and their electrical transport depends on the adsorption/desorption phenomenon of chemical substances which attach to the surface [12-17]. There are many one-dimensional (1D) $\mathrm{ZnO}$ nanostructures such as nanorods, nanowires, nanobelts, nanowalls, and nanotubes, among others, which have been synthesised through different growth methods and based on these nanorods nanodevices like electric field-effect switching [18], single electron transistors [19], biological and chemical sensing [20], and luminescence [21], among others, which have been reported. The crystalline structure of $\mathrm{ZnO}$ is tetrahedral in which zinc $\left(\mathrm{Zn}^{2+}\right)$ and oxide $\left(\mathrm{O}^{2-}\right)$ ions are periodically arranged along the $c$-axis [18] and having two opposite crystallographic polar planes with different surface relaxation energies. It is the reason that mostly the growth of $\mathrm{ZnO}$ nanostructures increases along the $c$-axis. The positively charged $\mathrm{Zn}-(0001)$ and negatively charged $\mathrm{O}-\left(0001^{-}\right)$ions together possess polar surfaces, permanent dipole moment, and high polarization along the $c$-axis. The size of biological and chemical substances, which are being sensed, is almost the same to the diameter of $\mathrm{ZnO}$ nanorods, that is, $\mathrm{ZnO}$ nanorods are good transducers in generating the strong electrical signals.

In this study, we have fabricated the $\mathrm{ZnO}$ nanorods on the gold-coated glass substrate and functionalised with dibenzyldiaza-18-crown-6 (DBzDA18C6) which is highly selective an ionophore for the detection of thallium (I) ions. The proposed thallium (I) ion sensor based on the functionalised $\mathrm{ZnO}$ nanorods showed good linear behaviour over the wide range of thallium ion concentrations $\left(1 \times 10^{-7}\right.$ to $\left.5 \times 10^{-2} \mathrm{M}\right)$ and offered negligible response towards the alkali metal ions and other common heavy metal interferents.

\section{Experimental Section}

2.1. Materials. Zinc nitrate hexahydrate $\left(\mathrm{Zn}\left(\mathrm{NO}_{3}\right)_{2}\right.$. $\left.6 \mathrm{H}_{2} \mathrm{O}\right)$, hexamethylenetetramine $\left(\mathrm{C}_{6} \mathrm{H}_{12} \mathrm{~N}_{4}\right)$, etthylenedi-

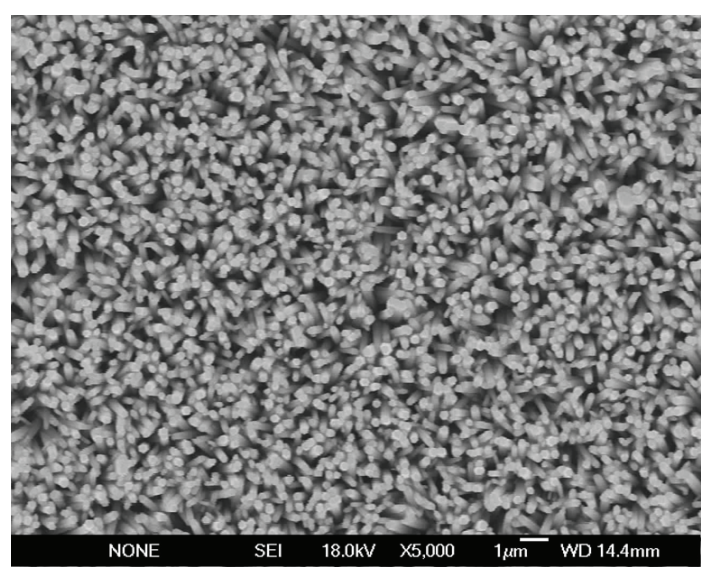

Figure 1: A typical FESEM image of $\mathrm{ZnO}$ nanorods grown on the gold coated glass substrate using hydrothermal growth method.

aminetetraacetic acid (EDTA), dibutyl phthalate (DBP), o-nitrophenyl octyl ether (o-NPOE), benzyl acetate (BA), tetrahydrofuran (THF), high molecular weight poly vinyl chloride (PVC), a selective thallium (I) ion ionophore dibenzyldiaza-18-crown-6 (DBzDA18C6), thallium nitrate $\left(\mathrm{TlNO}_{3}\right)$, sodium tetra phenyl borate (NaTPB), and all other interfering metal cations salts were purchased from Sigma Aldrich Sweden. The $\mathrm{pH}$ of testing solution was controlled by using the $1 \times 10^{-1} \mathrm{M}$ hydrochloric acid and $1 \times 10^{-1} \mathrm{M}$ sodium hydroxide. All other chemicals were used of analytical grade.

2.2. The Fabrication and Synthesis of the $\mathrm{ZnO}$ Nanorods. The procedure of fabrication of glass substrates and growth of $\mathrm{ZnO}$ nanorods are as described: The glass substrates were washed with isopropanol and sonicated in the ultrasonic bath for 10 minutes. Then, these were washed with deionized water and dried by nitrogen gas. Afterwards, these glass substrates were affixed in the vacuum chamber of evaporator Satis (CR 725) and $10 \mathrm{~nm}$ thin film of chromium (Cr) was evaporated then followed by the $100 \mathrm{~nm}$ thickness layer of gold $(\mathrm{Au})$. The growth of $\mathrm{ZnO}$ nanorods is as follows: firstly, these gold-coated glass substrates were cleaned with water and dried by nitrogen gas, and then a simple hydrothermal growth method was used for the growth of $\mathrm{ZnO}$ nanorods [22]. A homogeneous seed layer of zinc acetate dihydrate was produced on these glass substrates by using spincoating technique at 2500 r.p.m. for 25 seconds, and then substrates were annealed in the preheated oven for 20 minutes at $120^{\circ} \mathrm{C}$. Finally, these substrates were stuck on the Teflon sample holder and placed into an equimolar aqueous solutions of $\mathrm{Zn}\left(\mathrm{NO}_{3}\right)_{2} \cdot 6 \mathrm{H}_{2} \mathrm{O}$ and $\mathrm{C}_{6} \mathrm{H}_{12} \mathrm{~N}_{4}$, then, kept into the oven for 6 to 8 hours at $96^{\circ} \mathrm{C}$. When the growth time was completed, the substrates were washed with deionized water in order to remove the solid residual particles and dried by the nitrogen gas. After that, the morphology of grown $\mathrm{ZnO}$ nanostructures was studied by the field emission scanning electron microscopy (FESEM) and we observed that the grown $\mathrm{ZnO}$ nanorods were highly aligned and well controlled in length as shown in Figure 1. 
2.3. The Functionalization of $\mathrm{ZnO}$ Nanorods with Selective Thallium (I) Ion Ionophore. For the functionalization of $\mathrm{ZnO}$ nanorods, we used different amounts of ionophore, PVC, various plasticizers, such as DBP, o-NPOE, BA, and additive NaTPB into $3 \mathrm{~mL}$ of THF. After optimization, we found that $8 \mathrm{mg}$ of DBzDA18C6, $170 \mathrm{mg}$ of PVC, $60 \mathrm{mg}$ of o-NPOE, and $1 \mathrm{mg}$ NaTPB have shown the best results regarding to sensitivity, selectivity, detection range of thallium (I) ion concentrations, and so forth. The $\mathrm{ZnO}$ nanorods grown on gold-coated glass substrate were functionalised with this ionophore solution for 3-5 minutes and dried for 12 hours and kept at $4^{\circ} \mathrm{C}$ when not in use. The thallium (I) ion sensor was used as a working electrode in conjunction with $\mathrm{Ag} / \mathrm{AgCl}$ as a reference electrode for the potentiometric measurement of thallium (I) ion for the concentration range of $1 \times 10^{-7} \mathrm{M}$ to $5 \times 10^{-2} \mathrm{M}$. The output response of each thallium (I) concentration solution was measured using $\mathrm{pH}$ meter (model $744 \mathrm{Metrohm}$ ). The time response of the thallium (I) ion-sensor electrode was measured using electrical instrument Keithley 2400.

\section{Result and Discussion}

3.1. The Output Response of the Thallium (I) Ion-Sensor Electrode Based on Functionalized $\mathrm{ZnO}$ Nanorods. The electrochemical representation of thallium (I) ion-sensor electrode is given by following way:

$$
\mathrm{Au}|\mathrm{ZnO}| \text { ionophore } \| \text { thallium nitrate solution } \| \mathrm{Cl}^{-1}|\mathrm{AgCl}| \mathrm{Ag} \text {. }
$$

The response time of ion-sensor electrode mainly depends on the concentration of being tested an electrolyte and as the number of ions of tested analyte changes into the solution during the measurements, then the output response of ion-sensor electrode also alters. During the experiment, when thallium (I) ion sensor electrode was employed into the $1 \times 10^{-7}$ to $1 \times 10^{-1} \mathrm{M}$ thallium nitrate solution, we have observed that the ion sensor responded very well up to $5 \times 10^{-2} \mathrm{M}$, but after $5 \times 10^{-2} \mathrm{M}$ concentration, the ion sensor was sensing the thallium (I) with low output voltage due to the saturation limit of proposed ion-sensor electrode. The output response of thallium ion sensor for $1 \times 10^{-7}$ to $5 \times 10^{-2} \mathrm{M}$ concentration of thallium (I) ion is shown in the calibration curve of the logarithm concentration of thallium (I) ion versus the output voltage response in Figure 2. From Figure 2, it can be observed that the proposed ion sensor has responded according to the Nernst's equation for whole concentration range.

Thallium (I) ion sensor has shown good linearity for a large dynamic concentration $1 \times 10^{-7}$ to $5 \times 10^{-2} \mathrm{M}$ of thallium ion and better sensitivity about $36.87 \pm 1.49 \mathrm{mV} /$ decade with a regression coefficient $R^{2}=0.98$. The advantages of the proposed thallium ion sensor based on the functionalised $\mathrm{ZnO}$ nanorods with DBzDA18C6 are the lower detection limit $1 \times 10^{-7} \mathrm{M}$ concentration of thallium ion and fast response time of less than 5 seconds, which is better than the previous work based on the same ionophore used for the detection of thallium ion [23]. These obtained results of linearity, lower limit of detection, sensitivity, and fast response time of the present selective thallium ion sensor favour to use it for the detection of trace amount of thallium ion from the biological and environmental samples.

3.2. The Effect of Thallium Ion Concentration on the Response Time of Thallium (I) Ion-Sensor Electrode. In this study, we investigated that the response time of thallium ion sensor depends on the ionic concentration of thallium ion into testing solution. We tested the ion-sensor electrode into each concentration and found that the sensor showed about $15 \mathrm{~s}$ response time for $1 \times 10^{-7} \mathrm{M}$ concentration of thallium ion and for $1 \times 10^{-2} \mathrm{M}$ thallium ion concentration the response time was less than $5 \mathrm{~s}$ as shown in Figure 3. However, for higher concentration, the response time was also observed less than $5 \mathrm{~s}$. This is most probably due to fast kinetic complex reaction of thallium ion with the ionophore on functionalised $\mathrm{ZnO}$ nanorods [9].

\subsection{The Effect of $p H$ and the Interfering Ions on the Output} Response of the Thallium Ion Senor. The $\mathrm{pH}$ of analyte solution has also an influence on the response of ion-sensor electrode and we have examined this effect on the $1 \times$ $10^{-3} \mathrm{M}$ thallium ion solution for the $\mathrm{pH}$ range 3 to 12 as shown in Figure 4. It can be inferred from the $\mathrm{pH}$ calibration curve that response of thallium ion sensor was found almost the same from $\mathrm{pH}$ range 4 to 10 , but above $\mathrm{pH} 10$, the output voltage response was lowered because of the result of hydroxyl $\left(\mathrm{OH}^{-1}\right)$ ion. Below $\mathrm{pH}$ 4, the output response was also observed in decreasing order due to the two reasons, firstly that $\mathrm{ZnO}$ nanorods are very sensitive to higher acidic medium and start to dissolve into the testing solution [24] and another possible reason may be that the crown ether may act as base, accept the proton and make less chances for the complexion with thallium ion [25]. For evaluating the performance of a sensor, selectivity is the basic parameter and we observed selectivity in two different experiments. In the first experiment, we followed the mixed method and tested the thallium ion-sensor electrode in the thallium ion $1 \times 10^{-4} \mathrm{M}$ solution in the presence of interfering ions for concentration range $1 \times 10^{-7}$ to $5 \times 10^{-1} \mathrm{M}$ with addition of one $\mathrm{mL}$ of each interfering ion. We found that there was no significant effect of interfering ions on the output response of thallium ion sensor as shown in Figure 5. For confirming the either effect of higher volume of interfering ions, we increased the volume of interfering ions from $1 \mathrm{~mL}$ to $3 \mathrm{~mL}$ but we found that the sensor electrode responded the same 


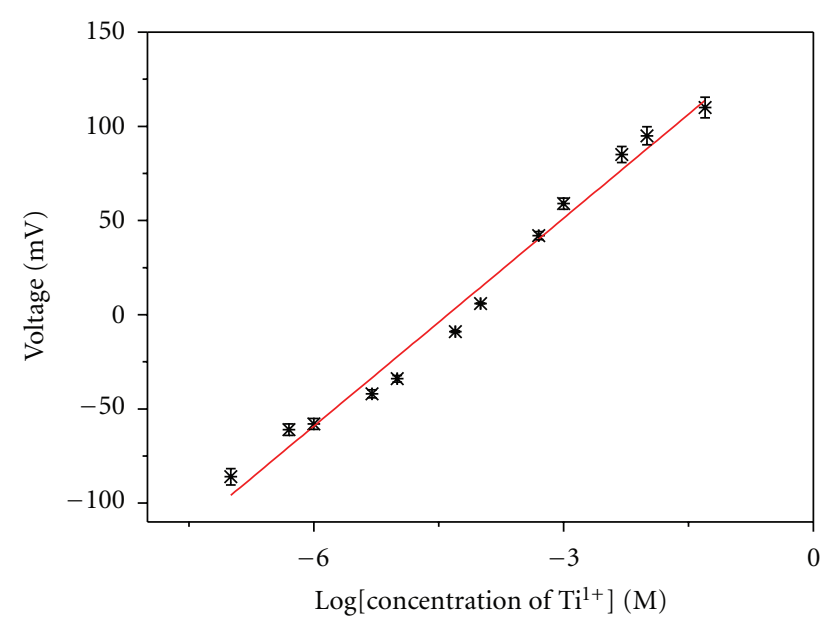

Figure 2: Calibration curve for thallium ion sensor.

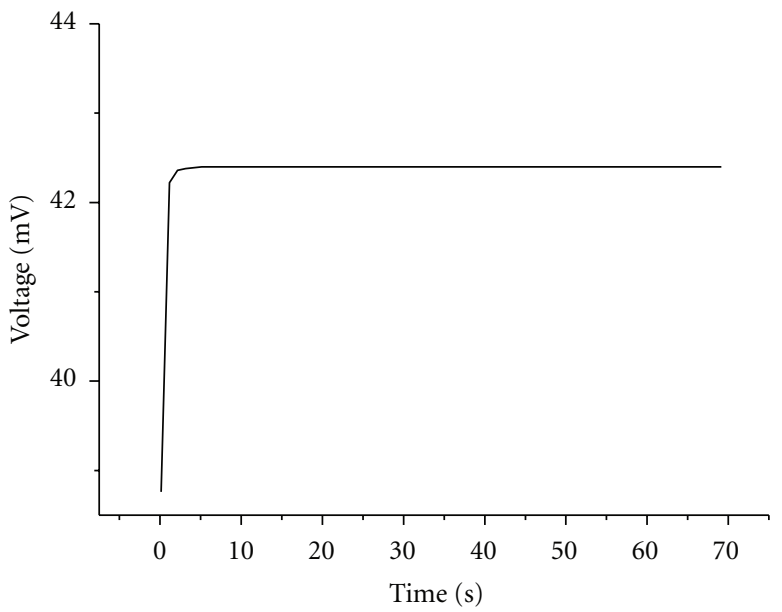

Figure 3: Time response of thallium (I) ion sensor in $1 \times 10^{-2} \mathrm{M}$ solution of thallium nitrate.

as with $1 \mathrm{~mL}$ of interfering ions. On another experiment, we used the separation method for determination of selectivity coefficient and we tested the thallium ion-sensor electrode into the $1 \times 10^{-4} \mathrm{M}$ thallium ion solution and separately to $1 \times 10^{-4} \mathrm{M}$ solution of each interfering ion. The calculated selectivity coefficient constant for each interfering ion is given in Table 1. It was observed during the experiment that the proposed thallium ion-sensor electrode showed good selectivity in the presence of interfering ions.

\subsection{Study of Reproducibility and Durability of Proposed Thal-} lium (I) Ion Sensor. The aim of this study was to examine the output response of one sensor to another sensor. We functionalised the five independent sensor electrodes based on $\mathrm{ZnO}$ nanorods and tested into the $1 \times 10^{-4} \mathrm{M}$ solution of thallium (I) ion, it was observed that each thallium ion-sensor electrode has shown good output response of reproducibility with relative standard deviation less than $3 \%$ as shown in Figure 6. In order to investigate the life time of thallium (I) ion-sensor electrode, we regularly tested

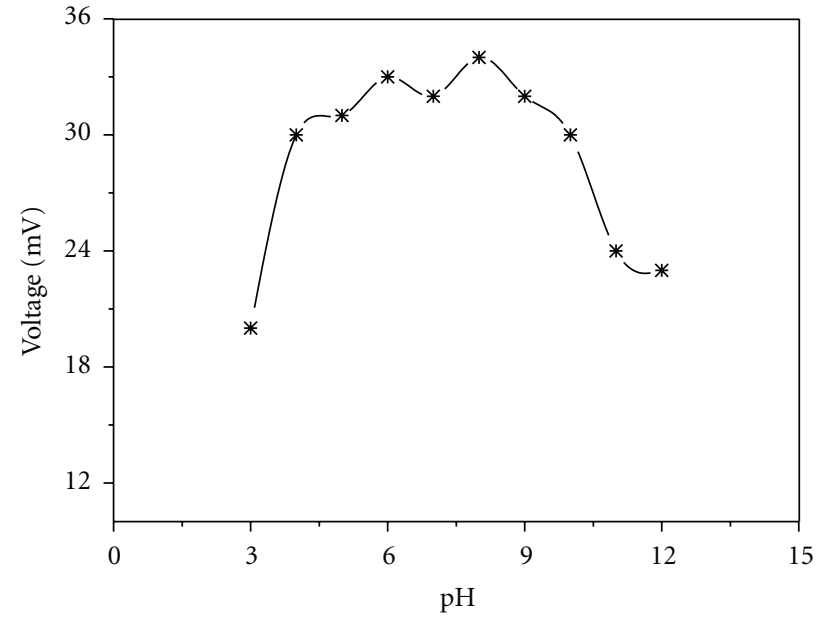

FIGURE 4: The effect of $\mathrm{pH}$ on the output response of thallium (I) ion sensor.

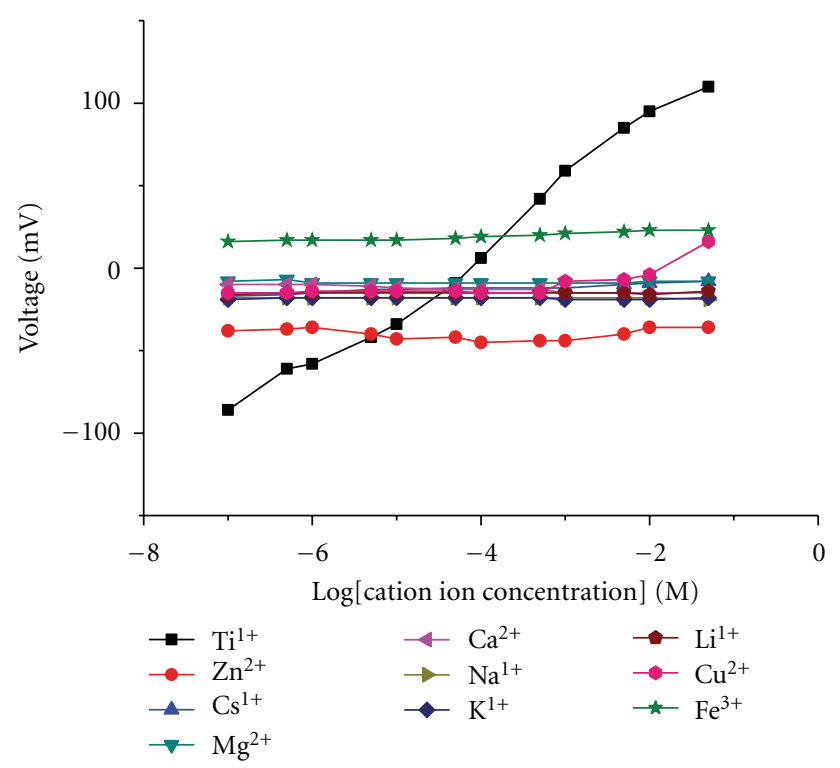

Figure 5: The behaviour of thallium ion sensor in the presence $1 \times$ $10^{-4} \mathrm{M}$ of interfering ions.

the thallium ion-sensor electrode for about four weeks. We found that thallium ion-sensor electrode maintained its detection range, sensitivity, repeatability, and we followed the Nernst's behaviour for four weeks except that in the fourth week, the detection range was changed from $1 \times 10^{-7}$ to 1 $\times 10^{-6} \mathrm{M}$ as shown in Table 2. This decrease in the detection range might be due to slight detachment of ionophore from the surface of functionalised $\mathrm{ZnO}$ nanorods with passage of time.

3.5. The Proposed Application of the Thallium Ion Sensor. The aim of this study was to find out the practical application of the present ion sensor and for this reason we used the ion-sensor electrode as an indicator electrode for the potentiometric titration of thallium (I) ion under the room 
TABLE 1: The logarithm of the selectivity coefficient of the thallium ion sensor for different interferents in $1 \times 10^{-4} \mathrm{M}$.

\begin{tabular}{lc}
\hline Interference (B) & $-\log K_{\mathrm{Tl} . \mathrm{B}}^{\text {pot }}$ \\
\hline $\mathrm{K}^{1+}$ & 4.65 \\
$\mathrm{Ca}^{2+}$ & 4.63 \\
$\mathrm{Na}^{1+}$ & 4.66 \\
$\mathrm{Mg}^{2+}$ & 4.40 \\
$\mathrm{Li}^{1+}$ & 4.55 \\
$\mathrm{Cu}^{2+}$ & 4.11 \\
$\mathrm{Cs}^{1+}$ & 4.33 \\
$\mathrm{Fe}^{3+}$ & 3.50 \\
\hline
\end{tabular}

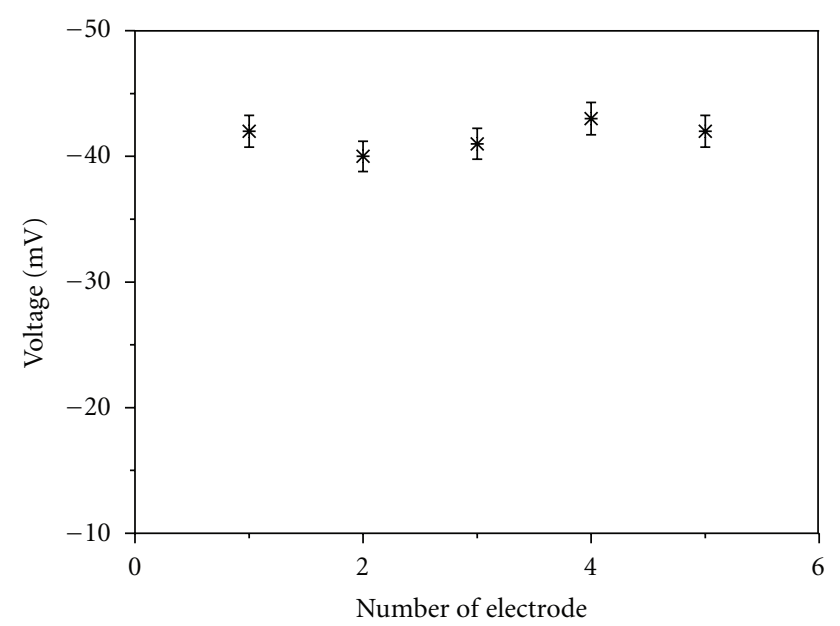

FIgURE 6: The sensor to sensor response in the $1 \times 10^{-5} \mathrm{M}$.

TABLE 2: Representing the durability of thallium (I) ion sensor.

\begin{tabular}{lcc}
\hline Number of days & Slope $(\mathrm{mV} /$ decade $)$ & Linear range $(\mathrm{M})$ \\
\hline 1 day & $36.87 \pm 1.49$ & $1 \times 10^{-7}-5 \times 10^{-2}$ \\
1 week & $37.10 \pm 2.20$ & $1 \times 10^{-7}-5 \times 10^{-2}$ \\
2 weeks & $36.62 \pm 2.44$ & $1 \times 10^{-7}-5 \times 10^{-2}$ \\
3 weeks & $36.69 \pm 2.56$ & $1 \times 10^{-7}-5 \times 10^{-2}$ \\
4 weeks & $35.53 \pm 1.12$ & $1 \times 10^{-6}-5 \times 10^{-2}$ \\
\hline
\end{tabular}

temperature conditions. We essayed the ion sensor electrode in titration of $18 \mathrm{~mL}$ of $2 \times 10^{-3} \mathrm{M}$ solution of thallium ion against the $5 \times 10^{-2} \mathrm{M}$ EDTA solution as shown in Figure 7. The titration curve revealed a good stoichiometric relation for the determination of thallium ion from unknown samples, due to this evidence thallium ion-ssensor electrode based on functionalised $\mathrm{ZnO}$ nanorods can be used as an indicator electrode. The $\mathrm{pH}$ and ionic strength were not adjusted during the experiments.

\section{Conclusion}

In the present work, we have built up a thallium (I) ion selective electrode based on the functionalized $\mathrm{ZnO}$ nanorods with DBzDA18C6. The proposed ion sensor has demonstrated excellent linearity for $1 \times 10^{-7} \mathrm{M}$ to $5 \times 10^{-2} \mathrm{M}$

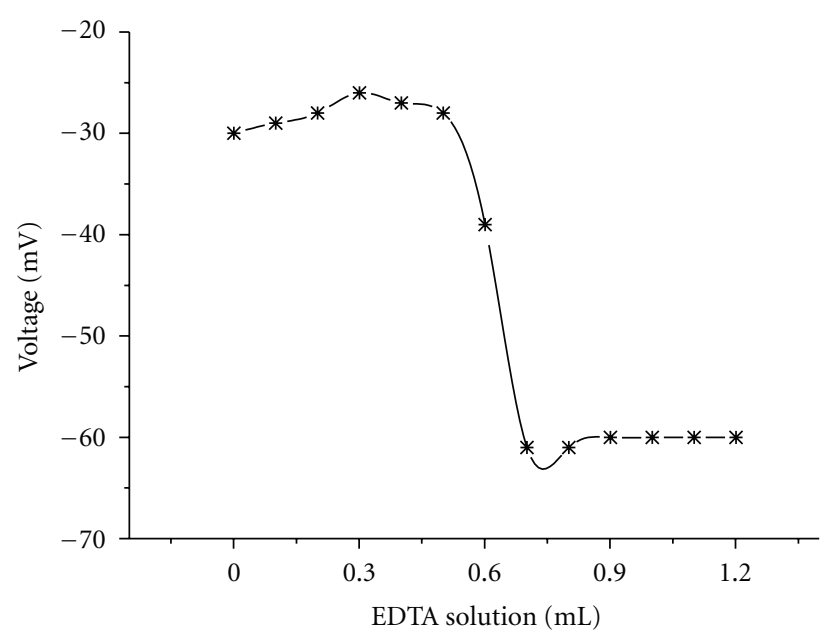

FIgURE 7: The potentiometric titration curve of thallium (I) ion sensor for $18 \mathrm{~mL}$ of $2 \times 10^{-3} \mathrm{M}$ thallium nitrate solution with $5 \times$ $10^{-2} \mathrm{M}$ solution of EDTA.

thallium ion concentration, high selectivity against the common interfering ions, good sensitivity about $36.87 \pm$ $1.49 \mathrm{mV} /$ decade, reproducibility, and stability for more than three weeks, and fast response time less than $5 \mathrm{~s}$. For practical application, the thallium ion sensor electrode was used as an indicator electrode in the potentiometric titration and the sensor electrode showed better stochiometric relation for the determination of thallium ion. All the obtained results indicate that the present thallium ion sensor can be used for the determination of trace quantities of thallium ion from environmental and biological samples.

\section{References}

[1] A. A. Abdel Gaber, "New thallium(I) ion selective electrode based on indeno pyran compound," Sensors and Actuators, B, vol. 96, no. 3, pp. 615-620, 2003.

[2] T. Katsu, K. Ido, K. Takaishi, and H. Yokosu, "Thallium(I)selective membrane electrodes based on calix[6]arene or calix[5] arene derivatives," Sensors and Actuators, B, vol. 87, no. 2, pp. 331-335, 2002.

[3] J. S. Britten and M. Blank, "Thallium activation of the $\left(\mathrm{Na}^{+}-\right.$ $\mathrm{K}^{+}$)-activated ATPase of rabbit kidney," Biophys, Biochemica and Biophysica Acta, vol. 159, no. 1, pp. 160-166, 1968.

[4] F. J. Kayne, "Thallium (I) activation of pyruvate kinase," Archives of Biochemistry and Biophysics, vol. 143, no. 1, pp. 232-239, 1971.

[5] K. S. Park, S. O. Jung, S. S. Lee, and J. S. Kim, "Thallium(I)selective electrodes based on calix[4]pyrroles," Bulletin of the Korean Chemical Society, vol. 21, no. 9, pp. 909-912, 2000.

[6] I. A. Rutkowska, J. Stroka, and Z. Galus, "Electrochemical properties of modified copper-thallium hexacyanoferrate electrode in the presence of different univalent cations," Electrochimica Acta, vol. 53, no. 11, pp. 3870-3878, 2008.

[7] S. S. M. Hassan, M. B. Saleh, A. A. Abdel Gaber, and N. A. Abdel Kream, "DDB liver drug as a novel ionophore for potentiometric barium (II) membrane sensor," Talanta, vol. 59, no. 1, pp. 161-166, 2003. 
[8] K. Kimura, K. Tatsumi, M. Yokoyama, M. Ouchi, and M. Mocerino, "Remarkable thallium(I) selectivity for ion sensors based on $\pi$-coordination of calix[4]arene neutral carriers," Analytical Communications, vol. 36, no. 6, pp. 229-230, 1999.

[9] G. Khayatian, S. Shariati, and A. Salimi, "Thallium(I)-selective membrane potentiometric sensor based on dibenzyldiaza-18crown-6," Bulletin of the Korean Chemical Society, vol. 24, no. 4, pp. 421-425, 2003.

[10] S. Moeschlin, "Thallium intoxication: clinicopath ological aspects of four cases," Clinical Toxicology, vol. 17, pp. 133-146, 1980.

[11] L. C. Tien, P. W. Sadik, D. P. Norton et al., "Hydrogen sensing at room temperature with Pt-coated $\mathrm{ZnO}$ thin films and nanorods," Applied Physics Letters, vol. 87, no. 22, Article ID 222106, 2005.

[12] T. J. Hsueh, S. J. Chang, C. L. Hsu, Y. R. Lin, and I. C. Chen, "Highly sensitive $\mathrm{ZnO}$ nanowire ethanol sensor with $\mathrm{Pd}$ adsorption," Applied Physics Letters, vol. 91, no. 5, Article ID 053111, 2007.

[13] Q. H. Li, T. Gao, Y. G. Wang, and T. H. Wang, "Adsorption and desorption of oxygen probed from $\mathrm{ZnO}$ nanowire films by photocurrent measurements," Applied Physics Letters, vol. 86, no. 12, Article ID 123117, 3 pages, 2005.

[14] X. J. Huang and Y. K. Choi, "Chemical sensors based on nanostructured materials," Sensors and Actuators, B, vol. 122, no. 2, pp. 659-671, 2007.

[15] C. C. Li, Z. F. Du, L. M. Li, H. C. Yu, Q. Wan, and T. H. Wang, "Surface-depletion controlled gas sensing of $\mathrm{ZnO}$ nanorods grown at room temperature," Applied Physics Letters, vol. 91, no. 3, Article ID 032101, 2007.

[16] R. Ghosh, M. Dutta, and D. Basak, "Self-seeded growth and ultraviolet photoresponse properties of $\mathrm{ZnO}$ nanowire arrays," Applied Physics Letters, vol. 91, no. 7, Article ID 073108, 2007.

[17] Y. Qiu and S. Yang, " $\mathrm{ZnO}$ nanotetrapods: controlled vaporphase synthesis and application for humidity sensing," Advanced Functional Materials, vol. 17, no. 8, pp. 1345-1352, 2007.

[18] J. Y. Park, D. E. Song, and S. S. Kim, "An approach to fabricating chemical sensors based on $\mathrm{ZnO}$ nanorod arrays," Nanotechnology, vol. 19, no. 10, Article ID 105503, 2008.

[19] G. T. Kim, J. Muster, V. Krstic et al., "Field-effect transistor made of individual $\mathrm{V}_{2} \mathrm{O}_{5}$ nanofibers," Applied Physics Letters, vol. 76, no. 14, pp. 1875-1877, 2000.

[20] N. J. Stone and H. Ahmed, "Silicon single electron memory cell," Applied Physics Letters, vol. 73, no. 15, pp. 2134-2136, 1998.

[21] Y. Cui, Q. Wei, H. Park, and C. M. Lieber, "Nanowire nanosensors for highly sensitive and selective detection of biological and chemical species," Science, vol. 293, no. 5533, pp. 12891292, 2001.

[22] M. H. Huang, S. Mao, H. Feick et al., "Room-temperature ultraviolet nanowire nanolasers," Science, vol. 292, no. 5523, pp. 1897-1899, 2001.

[23] Z. L. Wang, X. Y. Kong, Y. Ding et al., "Semiconducting and piezoelectric oxide nanostructures induced by polar surfaces," Advanced Functional Materials, vol. 14, no. 10, pp. 943-956, 2004.

[24] M. R. Ganjali, T. Poursaberi, L. Haji-agha Babaei et al., "Highly selective and sensitive copper(II) membrane coated graphite electrode based on a recently synthesized Schiff's base," Analytica Chimica Acta, vol. 440, no. 2, pp. 81-87, 2001.

[25] A. Fulati, S. M. Usman Ali, M. Riaz, G. Amin, O. Nur, and M. Willander, "Miniaturized $\mathrm{pH}$ sensors based on zinc oxide nanotubes/nanorods," Sensors, vol. 9, no. 11, pp. 8911-8923, 2009. 

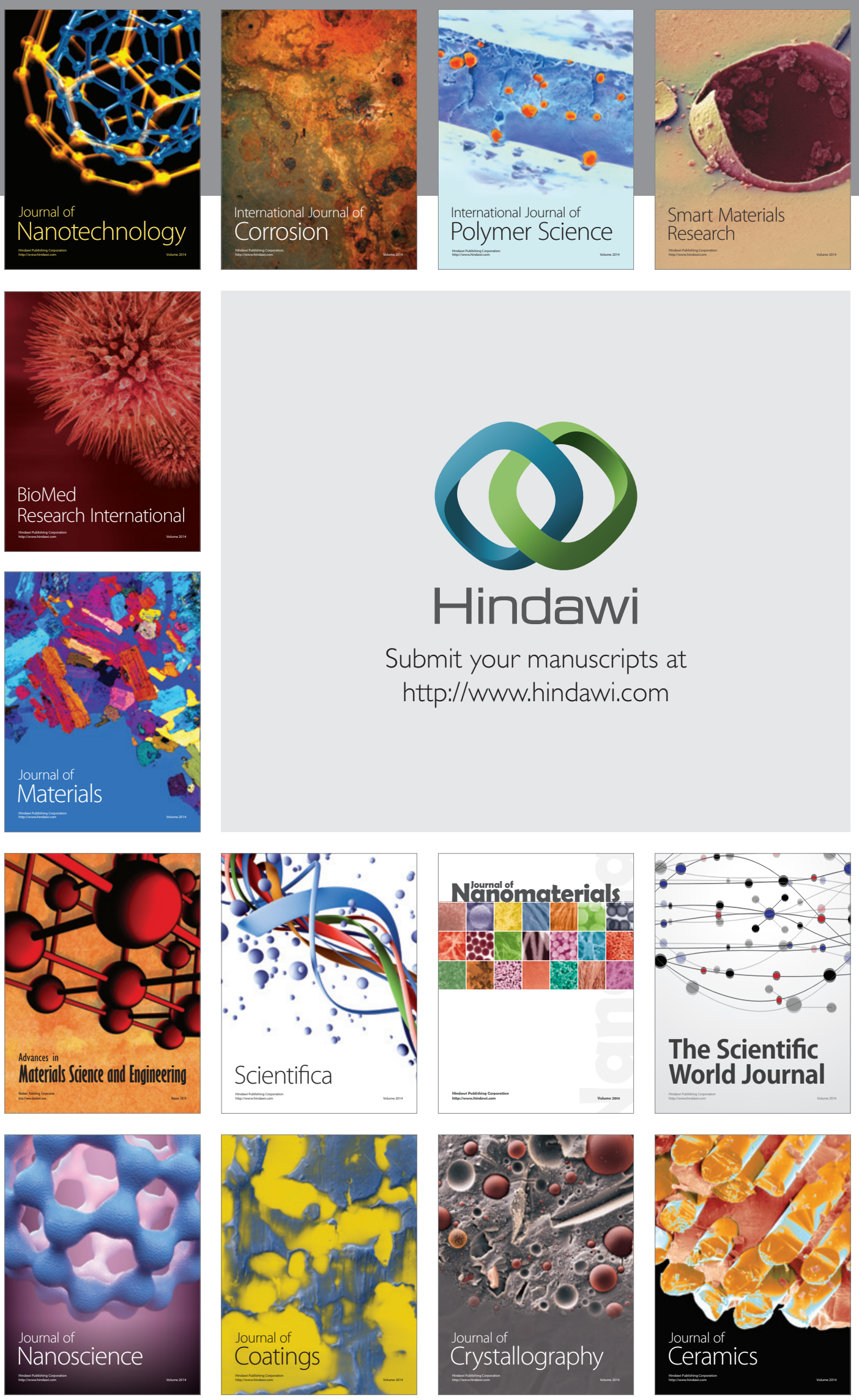

The Scientific World Journal

Submit your manuscripts at

http://www.hindawi.com

\section{World Journal}

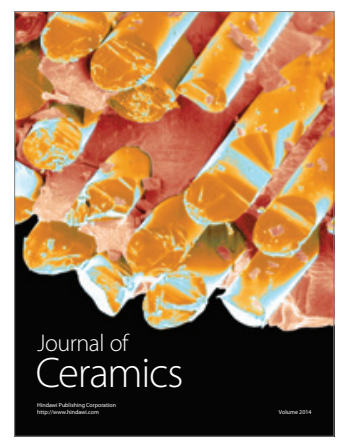

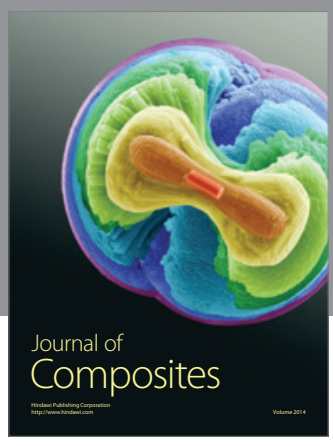
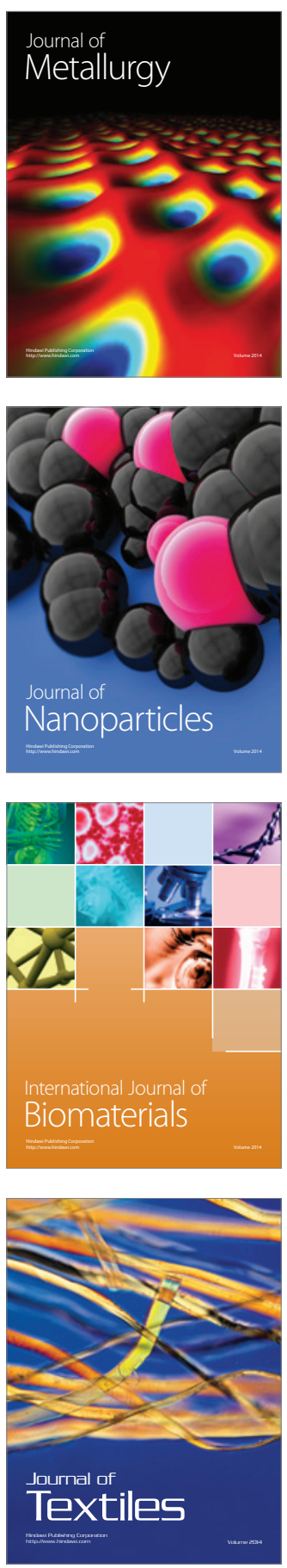